\title{
Funktionell familjeterapi - en behandlingsmetod vid ungdomskriminalitet
}

\section{KJELL HANSSON, MARIANNE CEDERBLAD \& BÖRJE HÖÖK}

\begin{abstract}
Trots utbredd behandlingspessimism har familjebehandling visat pä klara positiva resultat vid ungdomsasocialitet. Artikeln redovisar en randomiserad studie av behandling av dessa ungdomar. Resultaten är positiva och visar på vägar att bistå denna grupp ungdomar och deras familjer med relativt korta och strukturerade metoder.
\end{abstract}

\section{Inledning}

Ungdomskriminalitet är ett växande problem i mảnga länder, inte minst i Sverige där man fram till nyligen inte haft mänga behandlingsmetoder att tillgà vid detta problem. I Sverige har anmälda väldsbrotten, som begàtts av 15-17-äringar mot personer, mer än dubblerats fràn 1983 till 1993(Barnombudsmannen 1995). Vi vet ocksả att om ingenting görs för dessa ungdomar kommer kostnaderna för samhället att bli mycket höga (Statens ungdomsräd 1981). Forskning i Sverige sảväl som i andra länder om barn frản multiproblemfamiljer har visat att dessa familjer har psykiatriska problem, missbruk

Kjell Hansson är docent vid Socialhögskolan, Lunds universitet, Marianne Cederblad är professor vid Avdelningen för barn- och ungdomspsykiatri, Lunds universitet, Börje Höök är forskningsassistent vid Avdelningen för stressforskning, Institutionen för folkhälsovetenskap, Karolinska Institutet, Stockholm. hos föräldrarna, dälig arbetsanpassning, kriminalitet och somatiska problem sảväl som problem i familjen (West 1982, Nylander 1979, Rydelius 1979, 1981, Jonsson 1977, Wiberg 1976, Minuchin et al 1964, Minuchin et al 1967, Singer 1974). Barn som tidigt i livet blivit föremäl för insatser från socialvärden har ofta visat sig ha dảlig social anpassning i tonären (Andersson 1976, Sarnecki 1985).

Flera översiktsartiklar har visat att familjeterapi är en lovande metod för att behandla ungdomskriminalitet (Hazel rigg et al 1987). En av de metoder som tycks ha varit effektiv är funktionell familjeterapi. Den första arti-

Denna studie har finansierats av Forskningsrảdsnämnden (FRN). Vi vill ocksả tacka Eva Andersson och Per Johansson för deras psykoterapeutiska insatser samt socialsekreterare Anna-Kersti Hydèn pà Socialförvaltningen i Lund. Utan deras hjälp hade detta projekt inte kunnat genomföras. 
keln som visade lovande resultat publicerades redan 1973 (Alexander \& Parsons 1973, Parsons \& Alexander 1973). Sedan dess har funktionell familjeterapi använts pả flera olika ställen i USA för mer eller mindre allvarligt ungdomskriminella personer med mycket gott resultat (Klein, Alexander, \& Parsons 1976, Alexander \& Barton 1976, Barton, Alexander, Waldron, Turner \& Warburton 1985, Friedman 1989, Regas \& Sprenkle 1982, Gordon, Arbuthnot, Gustafson \& McGreen 1988, Gordon, Graves, \& Arbuthnot 1995). Även om flera studier i USA visat ett positivt resultat har man hittills inte använt denna metod i Sverige. Det är viktigt om vi ska använda metoder som utvecklats i t.ex. USA att vi försöker att anpassa dem till svenska förhällanden och prövar om de ocksả är tillämpliga i vảrt sociala system och vảr kultur.

Målet med denna artikel är att presentera resultatet frän en randomiserad studie, där man använt funktionell familjeterapi som behandlingsmetod vid ungdomskriminalitet. I denna artikel har vi begränsat resultatredovisningen till àterfallsfrekvens enligt officiella register och självdeklarerad psykisk hälsa.

\section{Metod}

\section{Undersökningsgrupp}

Alla ungdomar som blev tagna av polisen i Lund frản juni 1993 till juni 1995 utgjorde undersökningsgruppen. Alla som blev tagna inkluderades förutsatt att de hade gjort någonting som kunde rapporteras till sociala myndigheter. I studien exkluderades ungdomarna och deras familjer om de redan var under behandling av socialvärden eller barnpsykiatrin. Vi ville inte gà in med ytterligare en behandling för dessa familjer som redan var under behandling eller utredning. Ungdomarna och deras familjer skulle ocksà ha möjlighet att besvara de frägeformulär som vi hade vilket innebar att de borde kunna, àtminstone med hjälp, det svenska spräket. Totalt inkluderades 89 ungdomar, 49 ungdomar i FFT gruppen och 40 i jämförelsegruppen.

\section{Undersökningsprocedur}

När ungdomen blev tagen av polisen blev den socialsekreterare som var lokaliserad pà polisstationen informerad. Hon intervjuade regelmässigt ungdomen och hans/ hennes familj. Vid denna intervju bedömde hon om ungdomens och hans/hennes familj skulle inkluderas i projektet. Rutinmässigt informerade hon ungdomens föräldrar om vad som hänt, oftast genom personlig kontakt. Antingen àkte hon till föräldrarna eller kom föräldrarna till henne på polisstationen. Vi denna kontakt bedömde hon om familjen kunde inkluderas till forskningen och om sả var fallet genomfördes randomiseringen. Hon informerade därefter om det pảgäende forskningsprojektet och fràgade om de ville deltaga. Sedan föräldrar och ungdomar hade gätt med pả att deltaga gav hon oss vid Avdelningen för barn- och ungdomspsykiatri namn och telefonnummer till familjen. En forskningsassistent gjorde det första hembesöket för att samla in data. När det var gjort tog familjeterapeuten kontakt med familjen för att göra upp om en tid. Detta skedde oftast pà kliniken. Uppföljningsdata frän Socialförvaltningen samlades ocksả in av denna socialsekreterare framför allt eftersom hon hade 
tillgảng till informationen pả Socialförvaltningen och polisregistret. (Vi hade erhällit tillstảnd frản bảde föräldrar och myndigheter att genomföra detta) Vi hade information fràn tvà olika officiella register, polisregistret och anmälningar till socialförvaltning. Som en konsekvens av detta kunde vi fä information om alla som deltagit i studien. En uppföljning via hemintervjuer genomfördes tvà àr efter terapistart. Totalt ingick 49 familjer i FFT-gruppen och 19 familjer i jämförelsegruppen i testningar före behandlingen. Vid uppföljningen tvà àr efter behandlingsstart kunde vi inte motivera 3/49 familjer ur FFT-gruppen (6 procent) och 2/19 i jämförelsegruppen (11 procent). Det innebar att vi hade ett visst bortfall dả det gäller självsvarsdelen av studien. Det finns också internt bortfall för specifika formulär där nảgra av ungdomarna vägrade att medverka. Tjugoen av de 40 familjer som lottats till jämförelsegruppen deltog inte $\mathrm{i}$ forskningen genom att vägra besvara under-

\section{Tabell I}

Fördelning av ålder och kön för indexpersonerna

\begin{tabular}{lrrrr} 
Kön & & & & \\
Flickor & 6 & 12 & 6 & 15 \\
Pojkar & 43 & 88 & 34 & 85 \\
Total t & 49 & 100 & 40 & 100 \\
& & & & \\
Ailder & & & & \\
$10-11$ & 2 & 4 & 0 & 0 \\
$12-13$ & 6 & 12 & 1 & 3 \\
$14-15$ & 19 & 39 & 16 & 40 \\
$16-17$ & 20 & 41 & 22 & 55 \\
$18-$ & 2 & 4 & 1 & 3 \\
\hline
\end{tabular}

sökningsinstrumenten. Vi kunde emellertid följa upp samtliga ungdomar via registeruppgifter.

En statistisk jämförelse mellan de två grupperna visade att det fanns ingen skillnad dả det gällde kön och àlder. Ảldern pả FFT-gruppen var 14.7 (sd 1.8) och för jämförelsegruppen 15.5 (sd 1.2) àr. Familjernas socio-ekonomiska status var liknande som för Lund i övrigt.

Tabell 2 (se nästa sida) visar höga frekvenser av olika brott bảde för FFT-gruppen och Jämförelsegruppen. Skillnaderna mellan grupperna var smȧ och endast $i$ tvà fall finns signifikanta skillnader som gick i olika riktning. De brott som hade föranlett polisingripandet varierade mellan mindre stölder, vandalism, inbrott och rản. Samma frågeformulär har använts tidigare i en icke kriminell grupp. Vàr grupps självrapporterade antisociala beteende var 4-10 ggr högre än en normalgrupp (Ring 1996).

\section{Undersökningsinstrument}

Symptom Check List (SCL-90). Symptom Check List (SCL-90) (Derogatis et al. 1973), är en allmänt använd skala som bestàr av 90 item som tar upp psykologiska och emotionella symtom. Lảga värden indikerar god psykisk hälsa. Cronbach's alpha var .79. Formuläret har nu också standardiserats för svenska förhällanden (Malling Andersen \& Johansson, 1998).

\section{Achenbach's symtomlista (CBCL).} Achenbach har konstruerat flera olika versioner av symtomlistor som är ämnade att besvaras bland annat av föräldrar (CBCL) (Achenbach, 1991). Formuläret är översatt till 55 olika spräk inklusive svenska och är 


\begin{tabular}{|c|c|c|c|}
\hline Beteende & $\begin{array}{r}\text { Alla } \\
(n=66)\end{array}$ & $\begin{array}{r}\text { FFT } \\
(n=47)\end{array}$ & $\begin{array}{r}\text { Jämförelse } \\
(n=19)\end{array}$ \\
\hline Skolk & 76 & 77 & 74 \\
\hline Rymma hemifrån & 27 & 32 & 16 \\
\hline Köra utan körkort & 62 & 53 & 84 \\
\hline Snatterier & 74 & 77 & 68 \\
\hline Bilstölder & 20 & 28 & 0 \\
\hline Ficktjuv & 6 & 9 & 0 \\
\hline Inbrott & 37 & 37 & 37 \\
\hline Häleri & 24 & 26 & 21 \\
\hline Bära vapen (Kniv eller skjutvapen) & 52 & 49 & 58 \\
\hline Hotat människor & 12 & 15 & 5 \\
\hline Misshandel & 67 & 64 & 74 \\
\hline Cannabis missbruk & 24 & 28 & 16 \\
\hline Annat narkotikamissbruk & 3 & 4 & 0 \\
\hline Berusad flera gånger & 75 & 76 & 74 \\
\hline
\end{tabular}

en av de mest använda symtomlistorna i litteraturen (Larsson och Frisk, 1999). Formuläret är uppdelat i tvà delar; första delen utgörs av frägor som rör ungdomarnas kompetens och andra delen av olika pàstàenden som undersöker förekomst av olika problematiska symtom. I denna studie har endast symtomdelen använts. Skalan har 8 delskalor. Delskalorna 1-3 har sammanförts till ett större syndrom som kallats Internalisering och delskalorna 7-8 till Externalisering. Ett index för Total symtombelastning har ocksà beräknats.

KASAM (Känsla Av SAMmanhang). Självsvarsinstrumentet KASAM har utvecklats av Aaron Antonovsky för att mäta en livshällning, som kan öka motstảndskraften vid stress och därmed vara en hälsobefrämjande egenskap (Antonovsky 1991).
KASAM bestàr av 29 item med 7 svarsalternativ pà varje item. Poängen kan variera mellan 29-203. Instrumentet har i tidigare studier i Sverige visat sig ha en tillfredsställande validitet och reliabilitet (Hansson \& Cederblad 1995). Formuläret fylldes i av samtliga familjemedlemmar.

Självrapporterad asocialitet. Detta är ett formulär som är utvecklat vid Kriminologiska institutionen, Stockholms universitet (Ring 1996). I denna rapport har vi utnyttjat den del som innehảller förekomst av olika kriminella-eller antisociala beteenden. Man uppger dels om man genomfört en viss handling samt hur ofta. Formuläret har använts i andra sammanhang, där det gällt att beskriva normala ungdomars asociala beteende, varför det finns jämförelsemöjligheter. 


\section{Terapeutisk behandling- Funktionell familjeterapi}

Familjeterapin genomfördes i enlighet med Alexander \& Parsons beskrivning (1982). Funktionell familjeterapi har flera likheter med strukturell och strategisk familjeterapi. I enlighet med manualen är det viktigt att ha en klar struktur vid de terapeutiska sessionerna. (Terapeuten ska vara den som leder sessionen speciellt i början och det är ocksà viktigt att terapeuten har en förmȧga att utveckla en god kontakt med samtliga familjemedlemmar) (Barton \& Alexander 1977, Alexander \& Parsons 1982, Alexander 1998). Kommunikation är en viktig del ocksả i enlighet med den forskning som har bedrivits av Alexander m.fl. som har visat att det är viktigt att förändra den s.k. defensiva-försvarsinriktade kommunikationen till mer stödjande kommunikation. En annan behandlingsprincip är positiv omformulering (Robbins et al 1996). I tidigare studier har man visat att positiv omformulering är avgörande för ett positivt resultat. En annan viktig princip är att man redan i den diagnostiska fasen försöker förstà det antisociala beteendet sảsom en funktion av önskan att vara nära eller ha avständ i familjen. I denna modell menar man att varje individ har ett behov av närhet respektive avstànd som är specifikt för den individen. Man menar att var och en strävar att tillfredsställa detta behov sà att en person som har stort behov av närhet försöker skaffa sig och tillfredsställa detta behov genom olika manövrer i en familj. Dà det gäller det antisociala beteendet så menar Alexander att detta kan vara en funktion av just detta behov. Man beter sig antisocialt för att tillfredsställa ett sảdant individuellt behov. Enligt de behandlings- principer man talar om är det därför viktigt att tidigt diagnosticera detta behov och inte försöka ändra det utan snarare försöka ändra sättet att tillfredsställa behovet. Den funktionella familjeterapigruppen hade i genomsnitt fätt 10,0 sessioner med en spridning pà 3-32 sessioner. En familj som hade lottats till funktionell familjeterapi vägrade att komma till behandling medan alla de familjer som hade startat terapi avslutade denna i överenskommelse med terapeuten. För tvà av FFT-familjerna kom inte ungdomen medan resten av familjen deltog i sessionerna. I studien ingick fem olika familjeterapeuter medan tvà hade huvudansvaret för familjerna. EA hade 26 familjer, PJ 13 familjer. De övriga 10 familjerna var uppdelade på tre olika terapeuter. Alla terapeuterna hade fätt undervisning i funktionell familjeterapi direkt av professor Alexander och hade studerat hans metod genom att titta pả videoinspelade sessioner från USA. De hade också läst de manualer som finns. Samtliga terapeuter arbetade efter funktionell familjeterapi i det här projektet, även om de använder andra metoder i sitt övriga kliniska arbete. Under terapin har terapeuterna fätt handledning ungefärligen en gảng i mảnaden eller när terapeuterna begärde speciell konsultation. I ett par fall hade man direkthandledning där handledaren kallades in till sessionen. Handledningen inkluderade videohandledning. Samtliga terapeuter var legitimerade familjeterapeuter. Familjerna träffades vanligtvis pả Barn- och ungdomspsykiatriska kliniken. I vissa fall önskade familjerna ha sessionerna pȧ andra ställen, vilket då tillmötesgicks. Jämförelsegruppen erhöll konventionell socialvärd. Alla erbjöds olika sorters behandlingar såsom individuella samtal 


\section{Tabell 3}

Aterfall $i$ brott ett ar efter behandlingens start

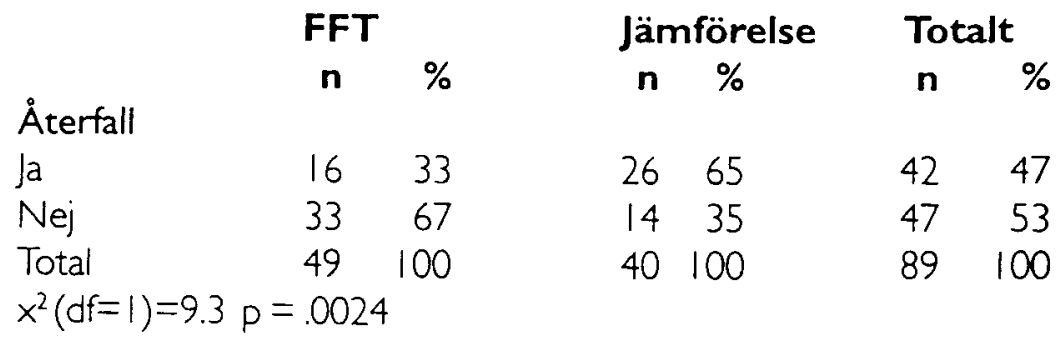

\section{Tabell 4}

Aterfall i brott tvà àr efter behandlingens start

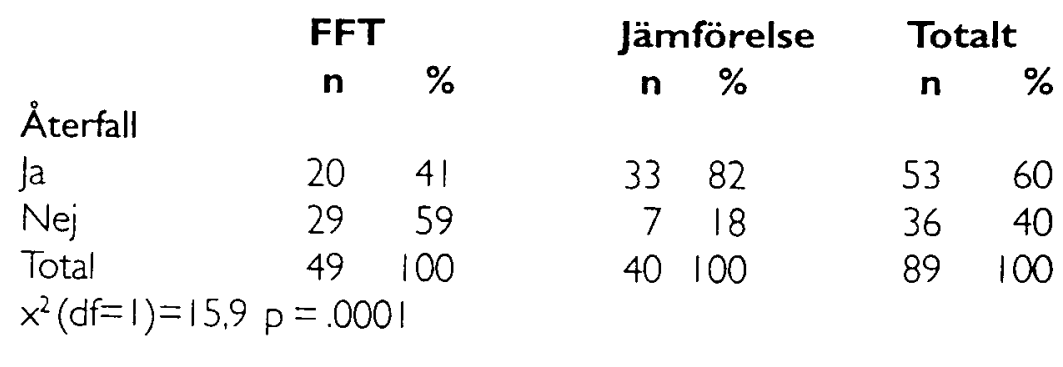

eller familjesamtal. I fyra av jämförelsegruppens familjer hade man remitterat dem till barnpsykiatrin.

\section{Resultat}

Ȧterfall har definierats som att man blivit tagen av polisen igen efter det att den funktionella familjeterapin hade startats eller aterigen blivit hänvisad till sociala myndigheter. I studien har vi inte differentierat mellan brott som man har blivit anklagad för eller fälld för.

Vi finner att bäde vid ett- och tväärsuppföljningen har FFT-gruppen signifikant bättre resultat än jämförelsegruppen. Vid bảda tillfällena är det dubbelt sả vanligt med àterfall i jämförelsegruppen.
Vi har här valt att presentera resultaten fràn självdeklarerad psykisk ohälsa utifrản en klinisk signifikans där vi vill visa hur mảnga som förbättrat sin situation från behandlingsstart till uppföljningen två år senare. I jämförelsegruppen har vi tyvärr ett stort bortfall men det gick inte att motivera familjerna för studien. Ett intressant fynd var att de som avböjde att deltaga vid uppföljningen hade klart större àterfallsfrekvens (90 procent) vid tvả ảr än de som deltog (74 procent). Detta gör att vi har skäl att misstänka att de 19 familjer ur jämförelsegruppen som deltog var ett positivt urval. Vid uppföljningen efter tvả àr deltog 94 procent familjer i FFT-gruppen och 43 procent i jämförelsegruppen. Vi har därför valt att presentera resultat endast fràn FFT-gruppen. Dessa resultat kan ses som ett sätt att 
försöka redovisa om de positiva resultaten i FFT-gruppen med avseende pả àterfallsfrekvens àtföljs av motsvarande symtomförändringar hos olika familjemedlemmar.

I Tabell 5 redovisas resultat för symtomformulären avseende patienterna. Flera patienter hade inte uppgivit symtomtyngd motsvarande klinisk nivȧ (medelvärdet + en standardavvikelse) enligt tidigare forskning (Larsson \& Frisk 1999, Malling Andersson et al 1998) varför dessa inte medtagits $i$ tabellen. Om man före behandling uppger làg symtommängd finns det inget skäl att anta att den ska minska som en följd av behandling. För FFT-gruppen var det 21/49 (43 procent) och för jämförelsegruppen 8/19
(42 procent) patienter som före behandlingen uppgav icke klinisk symtomtyngd.

Tabell 6 visar förändring av mammornas symtompoäng i de tvá grupperna. Man finner att 27 procent i bảda grupperna hade läga symtompoäng bảde före och efter behandling och skulle sảledes inte antas förändras. 49 procent i FFT-gruppen och 20 procent i jämförelsegruppen har minskat sina symtompoäng under observationsperioden. I bäda grupperna fanns mammor som hade "kliniskau värden bảde vid före och efter mätningen, dock klart flera i jämförelsegruppen. Signifikansprövning visade att det fanns en klar trend att FFT-gruppen i jämförelse med jämförelsegruppen uppvisar

\section{Tabell 5}

Symtomförändring under en tväarsperiod hos patienterna med kliniska ingängsvärden mätt via CBCL, SCL-90.

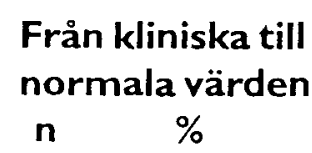

CBCL:

FFT $(n=28)$

SCL-90:

$\operatorname{FFT}(n=12)$
17

$9 \quad 75$

\section{Kvarstående kliniska värden \\ n $\%$}

$11 \quad 39$

325

\section{Tabell 6}

Mammornas förändring av symtomtyngd mätt med SCL-90 före behandling och efter tva arr.

\begin{tabular}{cll} 
Från höga & $\begin{array}{l}\text { Normala } \\
\text { till normala } \\
\text { både före } \\
\text { och efter }\end{array}$ & $\begin{array}{l}\text { Höga både } \\
\text { före och } \\
\text { efter }\end{array}$ \\
\hline
\end{tabular}

$\begin{array}{lrrrrrr}\text { FFT }(n=41) & 20 & 49 & 11 & 27 & 10 & 24 \\ \text { Jämförelsegrupp }(n=15) & 3 & 20 & 4 & 27 & 8 & 53\end{array}$


positiv förändring ("Höga till normala" jämfört med övrigt $X^{2}=3.76, p=.053$, Fisher's test $p=.07$ ), "Höga till normalau jämfört med "Höga bảde före och efter " $X^{2}=5.07, p=.02$, Fisher's test $\mathrm{p}=.04$ ).

Vid fortsatta analyser av FFT-gruppen via konventionella medelvärdesskillnader (t-test) fann vi flera intressanta skillnader. SCL-90 visar pả signifikanta sänkningar av symtommängden bảde för patienterna och deras mammor. För CBCL (mammornas symtomrapportering om barnen) finner vi signifikanta skillnader för patienterna för total symtombelastning samt för delsyndromen Externalisering och Internalisering. Vi finner ocksà en signifikant ökning av den sociala kompetensen för dessa ungdomar. Patienternas syskon beskrivs ocksả ha mindre symtombelastning efter behandling i FFT-gruppen.

Likartad analys har gjorts med resultatet fràn Känsla av sammanhang. Före behandling hade ca 32 procent av samtliga familjemedlemmar làg (s135 poäng) KASAM (medelvärde för pojkar i ảrskurs 9 är ca 145 och för vuxna ca 152) (Hansson \& Cederblad 1995). I denna analys har endast patienter medtagits. Av patienterna i FFT-gruppen som hade läga värden vid start av behandlingen hade 44 procent höjt sina värden till normalvärden medan motsvarande siffra i jämförelsegruppen var 23 procent. I FFT gruppen hade 35 procent av ungdomarna sänkt sina värden medan det i jämförelsegruppen var 67 procent som hade gjort detta. Dessa siffror bygger pả relativt fả personer och bör därför betraktas som tentativa. Hos föräldrar fanns det fä förändringar i KASAM.

\section{Diskussion}

Denna studie är en av de första randomiserade studierna inom detta omrädet iSverige. Vi kan konstatera att den svenska studien vid uppföljningar bảde vid ett och tvà àr visar goda resultat, helt motsvarande det man fann i studier fràn USA. I Figur 1 har nảgra studier jämförts med de svenska resultaten. Sannolikt är det en relativt tungt belastad grupp som vi arbetat med i Lund om man ser pả àterfallen i jämförelsegruppen. I de amerikanska jämförelserna har gruppen som blivit dömda för mer än 20 brott motsvarande àterfallsfrekvens(Barton et al 1985, Elliott et al 1999).

Jämförelserna är gjorda under ungefär samma premisser nämligen uppföljningar via officiella register. Det är viktigt att poängtera att här finns inget bortfall för de ungdomar som inte ville deltaga i den övriga uppföljningen.

Självsvarsformulären visar positiva resultat för FFT-gruppen. Det finns emellertid ett visst bortfall, speciellt i jämförelsegruppen, eftersom hälften inte velat deltaga i studien och att det finns ett visst internt bortfall genom att enskilda familjemedlemmar inte velat fylla i ett visst instrument. Detta har medfört att vi i huvudsak andvänt formulären för att undersöka förändringar i FFTgruppen.

Eftersom vi haft möjlighet att undersöka àterfallen för olika grupper har vi funnit att den grupp som inte velat deltaga i hela undersökningen har ett klart högre àterfall i kriminalitet. Det skulle kunna tyda pả att skillnaderna mellan grupperna skulle vara ännu mera till FFT-gruppens fördel. Ett intressant fynd är att vi lyckats få med 


\section{Figur I}

Resultat av tidigare studier av Funktionell Familjeterapi jämförda med denna studie (äterfall i procent, uppföljningstid inom parentes)

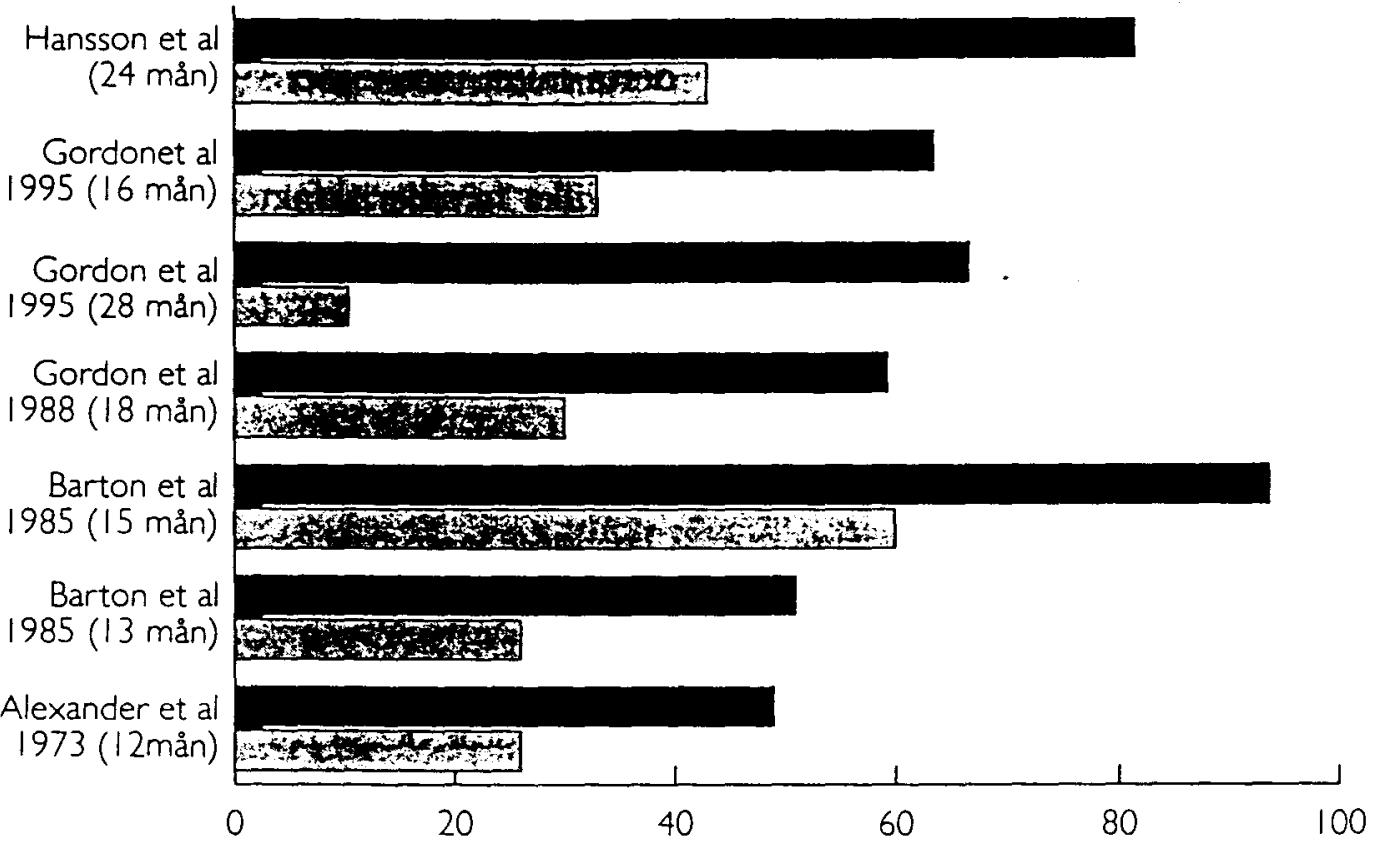

samtliga familjer, utom en, som lottats till FFT. Dessutom fullföljde samtliga familjer behandlingen sả att terapin avslutades i samförstảnd mellan terapeut och familj. Detta är ovanligt positivt med familjer med dessa problem. Flera forskare som sysslat med motsvarande grupper har redovisat bortfall upp till 50 procent (Henggeler et al 1986, Szapoznik et al 1983). Av de familjer som kom till behandling lyckades vi motivera samtliga ungdomar, utom 2 , att deltaga vid sessionerna.

I jämförelse med mảnga andra behandlingsmodeller visar vi pà mycket positiva resultat. Det kan finnas flera anledningar till detta utöver själva behandlingen. En möjlig förklaring kan vara att vi i studien fätt speciellt behandlingsmottagliga klienter vid den selektionsprocess vi haft. I studien ingàr t ex inga ungdomar som har pägàende behand- ling inom barnpsykiatrin eller socialförvaltningen. Det kan ocksả nämnas att vår undersökningsgrupp hade relativt sett hög socialgruppstillhörighet (Lund är en typisk akademikerstad) vilket kan pảverkat resultaten men förklarar inte gruppskillnaderna. Motsvarande studier pả andra orter och med andra urvalskriterier bör genomföras.

Vi har velat lyfta fram s.k. kliniskt relevanta förändringar, dvs om symtommängd har normaliserats eller ej. I den grupp som vi undersökt är det flera som sade sig inte uppleva psykiska problem i form av symtom. Dessa ska naturligtvis inte genomgà negativ förändring av behandlingen och bör heller inte förändras. Enkla medelvärden visar inte sädana resultat.

Förutomkliniska förändringar iFFT-gruppen kan vi ocksà visa att konventionella statistiska beräkningar ger positiva resultat före- 
trädesvis för patienter och deras mammor. Det är emellertid intressant att mammorna dessutom beskriver att syskon har mindre symtombelastning vid uppföljningen än vid behandlingens start. Klein et al (1976) har visat att àterfall i kriminellt beteende ocksả minskat hos syskon men har inte tidigare visat att psykiatrisk symtombelastning minskat. Utifrản ett systemteoretiskt perspektiv borde det vara sả att hela familjen pàverkas av behandlingen speciellt om man har ett arbetssätt som bjuder in samtliga familjemedlemmar.

Vid uppföljningen som gjordes i familjernas hem gavs ofta mycket positiva synpunkter på behandlingen och det bemötande som man hade fätt. Vi tror att det finns flera skäl till detta. Ett skäl var att vi försökte att komma i kontakt med familjerna sả snabbt som möjligt efter det att ungdomen hade blivit tagen av polisen (vårt arbetsnamn pả projektet var "Snabba insatseru). För familjerna var händelsen aktuell och man ville gärna tala om vad som hade hänt. Ett annat var att det i projektet ingick legitimerade familjeterapeuter som var intresserade av denna grupp klienter och deras familjer. Detta är inte alltid fallet inom den konventionella barnpsykiatrin där kriminella pojkar inte är önskepatienterna. Vi fick använda olika forskningsmedel för att bekosta behandlingen för halva projekttiden eftersom man inom barnpsykiatriska kliniken inte ville släppa till resurser förrän i senare delen av studien.
Ett annat skäl var naturligtvis att själva metoden var utprövad för just denna grupp och tydligen var användbaräven i densvenska kulturen. Att försöka följa en "manual« är inte de flesta terapeuters första val men i detta fallet visade det sig vara framgangsrikt. Manualen bygger pà tidigare forskning om vilka familjeriskfaktorer som leder till asocialt beteende och som man kan försöka avhjälpa med FFT-metoden. För att nå resultat är det möjligt att man mycket mera än nu "skräddarsyru behandling utifrån den grupp man ska hjälpa som i FFT. I psykosocialt behandlingsarbete sker detta ofta mera på känn än efter de forskningsresultat som finns.

Man borde ocksả närmare analysera vad i själva behandlingen som samvarierar med positiva resultat, vilka eller vilka delar av de terapeutiska interventionerna som är hjälpsamma för familjerna (se Robbins et al 1996). Vär förhoppning är att metoden kommer att sprida sig till framförallt socialförvaltningar och barnpsykiatriska kliniker där man bör arbeta med funktionell familjeterapi.

Vi tycker oss kunna konstatera att för denna grupp har behandlingen kunnat resultera i en klar minskning av àterfallsfrekvensen hos ungdomarna och förbättrad psykisk hälsa i FFT-gruppen. Vi har ocksả kunnat visa att det gär att genomföra randomiserade studier inom detta omrädet under förutsättning att man etablerar ett bra samarbete mellan de deltagande organisationerna. 


\section{Referenser}

Achenbach, T.M. (1991). Manual for Child Behavior Checklist 14-18 and 1991 Profile, Burlington V.T: University of Vermont.

Alexander, J.F. (1973) Defensive and supportive communications in normal and deviant families. Journal of Consulting and Clinical Psychology, 40, 2:223-231.

Alexander, J.F. (1998) Blueprints for violence prevention. Functional Family therapy. in. Elliott, D., \& Mihalic, S. Eds Blueprints for violence prevention and reduction. the identification and documentation of successful programs. Center for study and prevention of violence. University of Colorado, Institute of Behavioral Science.

Alexander, J.F. \& Parsons, B.V. (1982) Functional Family Therapy: Principles and Procedures. Carmel, CA: Brooks \& Cole.

Alexander, J.F. \& Barton, C. (1976) Systemsbehavioral intervention with families of delinquents: Therapist characteristics, family behavior, and outcome. Journal of Consulting and Clinical Psychology, 44,4, 656-664.

Alexander, J.F. \& Parsons, B.V. (1973) Short-term behavioral intervention with delinquent families: Impact of family process and recidivism. Journal of Abnormal Psychology, 81,3, 219-225.

Andersson, M. (1976) Hur gàr det för 50-talets Stockholmspojkar? En uppföljning av 222 vanliga skolpojkar och 100 Skảpojkar. Monografier utgivna av Stockholms kommunförvaltning, nr 38

Antonovsky, A. (1991) Hälsans Mysterium. Köping: Natur \& Kultur.

Barnombudsmannen (1995) Upp till 18.- Fakta om barn och ungdom. Statistiska centralbyràn, Bulls tryckeri, Halmstad

Barton, C. \& Alexander, J.F. (1977) Therapist skills as determinants of effective systems-behavioral family therapy. International Journal of Family Counseling, 11, 1-15.

Barton, C., Alexander, J.F., Waldron, H., Turner, C.W. \& Warburton, J. (1985) Generalizing tre- atment effects of Functional Family Therapy: Three replications. American Journal of Family Therapy, 13, 16-26.

Elliott, D.S. (ed) (1999) Blueprints for Violence Prevention. Center for the Study and Prevention of Violence, University of Colorado at Boulder, C \& M Press, Denver

Derogatis, L. R., Lipman, R. S. \& Covi, L(1973) SCL-90: An Outpatient Psychiatric Rating Scale- Preliminary Report. Psychopharmacology Bulletin 1, 13-28.

Friedman, A.S. (1989) Family therapy vs. parent groups: Effects on adolescent drug abusers. American Journal of Family Therapy, 17, 335-347.

Gordon, D.A., Arbuthnot, J., Gustafson, K.E. \& McGreen, P. (1988) Home-based behavioral-systems family therapy with disadvantaged juvenile delinquents. The American Journal of Family, 16, 243-255.

Gordon, D A., Graves, K. \& Arbuthnot, J. (1995) The effect of Functional Family Therapy for delinquents on adult criminal behavior. Criminal Justice and Behavior, 22, 60-73.

Hansson, K \& Cederblad, M. (1995) Känsla av sammanhang. Studier fràn ett salutogent perspektiv. Forskning om barn och familj, nr 6 , Institutionen för barn och ungdomspsykiatri, Lunds universitet.

Hazelrigg, M.D., Cooper, H.M. \& Borduin, C.M. (1987) Evaluating the effectiveness of family therapies: An integrative review and analysis. Psychological Bulletin, 101, 428-442.

Henggeler, S.W., Rodnick, J.D., Bourduin, C.M., Hanson, C.L., Watson, S.M. \& Urey, G.R. (1986) Multisystemic Treatment of Juvenile Defenders: Effects on Adolescent Behavioral and Family Interaction. Developmental Psychology Vol 22 No 1, 132-141,

Jonsson, G. (1977) Flickor pà glid. Tiden/Folksam, Stockholm.

Klein, N.C., Alexander, J.F. \& Parsons, B.V. (1976) Impact of family systems intervention on recidivism and sibling delinquency: A model of pri- 
mary prevention and program evaluation. Journal of Consulting and Clinical Psychology, 45, 469-474.

Kriminalvärdsstatistik (1994) Ȧterfall i bott. 177-183

Larsson, B. \& Frisk, M. (1999) Social competence and emotional/ behaviour problems in 6-16 year-old Swedish school children. European Child and Adolecent Psychiatry, 8, 24-33

Malling Andersen, S. \& Johansson, M. (1998) SCL-90 (Symptom checklist) En svensk normering och standardisering. Missbruksprojektet vid Institutionen för Tillämpad Psykologi, Lunds Universitet, Rapport no 3

Minuchin, S., Auerwald, E., King, C.H. \& Rabinowitz, C. (1964) The study and treatment of families that produce multiple acting-out boys. American Journal of Orthophysichiatry, 34, 125-133,

Minuchin, S., Montalvo, B., Guerney, B.G., Rosman, B.L. \& Schumer, F. (1967) Families of the slum. An exploration of their structure and treatment. Basic Books, New York

Nylander, I.A. (1979) A 20-year follow-up study of 2.164 cases at the child guidance in Stockholm. Acta Paediatr Scan, Suppl 276.

Parsons, B.V. \& Alexander, J.F. (1973) Short term family intervention: A therapy outcome study. Journal of Consulting and Clinical Psychology; 41,195-201.

Regas, S. \& Sprenkle, D. (1982) Functional family therapy with hyperactive adolescents. Paper presented to the Annual Meeting of the American Association for Marital \& Family Therapy. October, 1982.
Ring, J. (1996) Stöld, droger och vảld bland elever i ärskurs nio. Resultat frản den första rikstäckande undersökningen av elevers självrapporterade brottslighet och utsatthet för brott. Department of Criminology, Stockholm University.

Robbins, M.S., Alexander, J.F., Newell, R.M. \& Turner, C. W. (1996) The immediate effect of reframing on client attitude in family therapy. Journal of Family Psychology, 10, 28-34.

Rydelius, P-A. (1979) Alkoholmissbruk hos barn och ungdom. Läkartidningen 76, nr 25,

Rydelius, P-A. (1981) Children of alcoholic fathers. Their social adjustment and their health status over 20 years. Acta Paediatria Scandinavia, Suppl 286.

Sarnecki, J. (1985) Predicting Social Management. Stockholm: The National Council for Crime Prevention, Rapport 17.

Singer, M. (1974)Delinquency and family disciplinary configurations: An elaboration of the superego lacunae concept. Archives of General Psychiatry, 21, 795-798,

Statens Ungdomsräd. (1981) Ej till salu. Rapportserien Till varje pris. Liber

Szapocznik, J. et-al (1983) Conjoint versus oneperson family therapy: Some evidence for the effectiveness of conducting family therapy through one person. Journal of Consulting and Clinical Psychology. Dec; Vol 5l(6): 889-899.

West, D.J. (1982) Delinquency. Aldershot: Gower House.

Wiberg, E ed (1976) Pojkar i tvàngsvàrd- Rảbyundersökningen. Lund, Prisma. 